\title{
Communicating Climate Change in Kenya: Status, Challenges and Prospects
}

\author{
Elizabeth Momanyi \\ Department of Communication Studies \\ Kisii University, Kenya. \\ Benard 0.Nyatuka \\ Department of Educational Foundations \\ Masinde Muliro University of Science \& Technology \\ Kakamega, Kenya.
}

\begin{abstract}
Climate change remains a gigantic developmental issue the world over thus calling for sustainable intervention measures. Research shows that despite the potential dangers posed by climate change, public concern is low, a situation that tends to be linked to unfamiliarity with the nature of the climate uncertainties. One of the possible ways to address this scenario, it has been argued, is to apply research from communication and related fields to tailor messages to the existing perceptions, values and attitudes of different audiences in a bid to make the debate understandable, relevant and personally important. And, this is where journalists are called upon to not only present the complicated story, but make it comprehensible and appealing to a lay readership as well. But what challenges are they likely to face in communicating issues on climate change? To attain the goals envisioned in the Kenya Vision 2030 in particular, and socio-economic development in general, understanding climate change, its attendant consequences and the most appropriate means to tackle them is paramount. Specifically, this paper discusses the challenges facing journalists in covering climate change issues in Kenya. Prospects with respect to communicating climate change issues in the country are also explored. In an attempt to better understand this paper, a relevant theory is elucidated while the background information is presented including an overview of climate change, the status of the mitigation measures being employed as well as the role of the media in communicating this grave phenomenon.
\end{abstract}

Key words: Climate change, Challenges, Communication, Prospects, Mitigation and Kenya Vision 2030

\section{INTRODUCTION}

Evidently, climate change is a great global development challenge today that warrants sustainable intervention measures. According to the United Nations Environment Programme (UNEP ,2009), climate change refers to alteration in the state of the climate over time due to natural variability or as a result of human activity. Such variability leads to accelerated reduction of mountain glaciers, increased temperature, acidification in oceans, shifting climate zones and change in the earth's ecosystem as well as precipitation. Climate change arising from the emission of anthropogenic greenhouse gases like carbon dioxide released by burning of fossil fuels, forest depletion and emission of nitrogen oxides into the ozone layer, have all contributed to increases in atmospheric temperatures leading to global warming (UNEP, 2009). However, global greenhouse gas emission is continuing unabated with indications that climate change consequences are likely to worsen. Clearly, this trend needs to be reversed at 
all costs for the sake of maintaining the ecological balance required by the wide variety of flora and fauna, including humankind, in their various environments.

Like in any other part of the globe, Kenya has not been spared the effects of climate change and variability as at least 70 percent of its land mass is arid and semi-arid (ROK, 2010).Thus, if Kenya takes no action to minimize the current as well as expected impacts of climate change, the costs of potential damage to the economy will be enormous. Among others, the country will not be in a position to realize the goals as stipulated in the Kenya Vision 2030 including a safe and clean hence sustainable environment. Indeed, Kenya should take climate change seriously as it affects such critical issues as food security, health, natural resources, physical infrastructure, economic and social development and to some extent eradication of conflict especially among the nomadic pastoralists.

Unfortunately, many Kenyans neither understand what climate change means nor have ideas on the mitigation measures to apply. This is because they lack information and resources that would enable them to cope more effectively (BBC World Service Trust, 2009). Given this scenario, the media would be expected to play a pivotal role in the dissemination of information related to climate change. It is worth noting that the media informs and provides the public with a platform for articulating their views on various issues. Along with bringing in the hub of debates and discussions, the media attempts to suggest alternatives to the people and policymakers (Itai, 2005). However, although the impacts of climate change have been fairly documented, little has been done on the challenges facing journalists in covering issues on climate change.

Eskjaer (2009) argues that so far, climate change issues are documented using mainly quantitative techniques. Thus, little research involving the qualitative techniques, particularly with respect to how the media approach and frame climate change has been conducted. Accordingly, numerical analysis only presents a section of the story while qualitative approaches like editorial priorities as well as journalistic practices either increase or decrease the value of quantitative data. In an attempt to fill this knowledge gap therefore, this paper employ the qualitative approach to explore the challenges that hinder journalists from adequately reporting climate change issues. Further, the prospects with regard to communicating the phenomenon of climate change in Kenya is another focus of this paper.

\section{THEORETICAL FRAMEWORK}

This paper is informed by the Agenda Setting Theory as advanced by McCombs and Shaw (1972). It holds that the media has the power to present images to the public. It is based on the assumption that the media influences what people think about (Dearing and Rogers, 1996). Thus, what the public knows and cares about at any given time is mostly a product of media gatekeeping and agenda. Accordingly, gatekeepers selectively determine the agenda for what is news. Research shows that the media help shape people's minds, especially those that do not have a direct connection to reality. This means that topics that are not discussed in the media become less important or relevant to the public.

Although agenda setting focuses on the gate keeping ability of the media, other people besides journalists, editors and broadcasters can influence the media (Dainton \& Zelley, 2005). By selecting, excluding, emphasizing and elaborating certain aspects of news, public opinions are inevitably shaped and influenced. Thus the news media influences their audiences to think about selected issues in a certain perspective (McQuail, 2005). 
With regard to this paper therefore, there is need for the media to constantly publish and guide salient cues on issues of climate change and the environment as a whole. Among others, it should consistently set the agenda including putting pressure on the government and public to mitigate climate change because its effects are largely disastrous.

\section{OVERVIEW OF CLIMATE CHANGE AND KENYA VISION 2030}

It is a reality that one of the most serious challenges facing humankind at this historical juncture is that of climate change. For instance, climate change is known to induce the spread of diseases, drought, floods, conflict and insecurity in resource use, overgrazing and deforestation. Other consequences of climate change include, soil erosion and fertility decline, water scarcity, food insecurity as well as wood fuel crisis (Republic of Kenya-ROK, 2009). The challenges arising from climate change have apparently, taken centre stage in the global development agenda. Indeed, one of the eight Millennium Development Goals (MDGs) focuses on environmental sustainability.

The global average temperatures have risen both on land and in the oceans with observable impacts already occurring (ROK, 2009). In Kenya, there have been widespread changes in extreme temperature. Accordingly, data from the meteorological department shows that cold days and nights have become less frequent. Conversely, hot days and nights have become a common phenomenon (ROK, 2008).

The effects that the forecast rise in global temperatures will have on life on the planet are hard to overestimate (ENAJS, 2012). Kenya is already witnessing disappearance of the glaciers on Mount Kenya yet the country's hydropower potential is on the water system fed by the glacial melts from the mountain (ROK, 2009). Scientists project that the ice cap on the mountain should disappear by 2020 with negative environmental implications. Today, there are only seven glaciers on the mountain compared to 18 of them in 1900! Further, Lakes Victoria, Nakuru, Turkana, Baringo, Naivasha and Elmentaita have experienced serious declines in water levels. Similar drastic changes have been observed in the volumes of Rivers Athi and Tana thereby interrupting the generation of electricity in the country.

The risks that are associated with climatic change are particularly high to those communities that directly depend on natural resources for their livelihood. Kenya falls under this category. According to ROK (2008), about 42 percent of Kenya's GDP is derived from natural resource based sectors of agriculture, forestry, tourism, mining, energy, livestock and fisheries which are all climate- sensitive.

Kenya has been plagued by natural, weather - related disasters that cause, among others, diseases, deaths, destruction of property, infrastructure and general suffering throughout the nation. According to ROK (2007), over 70 percent of the natural disasters affecting the country are weather related and that in the recent past, there has been an increase in the frequency, magnitude and severity of the disasters. The most prevalent hazards are drought and flooding. Although these events are natural in origin, the impacts of human induced climate change are predicted to exacerbate them (Environment and Vision 2030, 2012). Meanwhile, it is evident that the frequency and occurrence of floods in many parts of the country have significantly increased since the 1990s.

On the other hand, environmental changes brought by human activity, such as deforestation, desertification, coastal modification, including the removal of mangrove and agricultural 
practices in fragile ecosystems contribute to an increase in the disastrous consequences of what were once purely natural weather hazards (Environment and Vision 2030, 2012).

As per Vision 2030 development plan (ROK, 2007), Kenya aims to be a nation that has a clean, secure and sustainable environment which is one of the key components of the global development agenda. Accordingly, the vision's social, economic and political pillars are interrelated and the fibre that binds them together is the natural environment, with its inherent supply of both renewable and non-renewable goods and services. Realization of Vision 2030 to a large extent depends on maintaining the natural systems that support agriculture, energy supplies, livelihood strategies and tourism, among others. To achieve this, it endeavors to employ such strategies as enhancing disaster preparedness in all the disasterprone areas as well as improving the capacity for adaptation to global climate change.

Clearly, climate change poses a major challenge to Kenya's social as well as economic wellbeing including human life and the environment itself. Coupled with the country's low adaptive capacity to climate change, there is a high level of vulnerability (ROK, 2008). Interestingly, although Kenya has contributed little to the causes of global warming, it is one of the countries most hit by the disasters of climate change (ROK, 2007). These effects are, however, likely to be more severe in the future, unless the international community demonstrates greater resolve. The situation is further complicated by the fact that the current approaches to disaster management in Kenya are geared towards disaster response as opposed to disaster risk reduction (ROK, 2007). Accordingly, this could slow down the country's projected economic growth as the economy is heavily dependent on such climate - sensitive sectors as agriculture, tourism and the coastal zones.

\section{STATUS OF CLIMATE CHANGE MITIGATION IN KENYA}

In order to achieve its development goals, including the targets under the MDGs and those related to Vision 2030, Kenya needs to effectively plan and manage its environmental, economic and human resources to avoid disasters, including those induced by climate change. Protecting and restoring environmental assets will help make Vision 2030's economic and social goals a reality (Environment and Vision 2030, 2012)

According to ROK (2008), proactive management of the environment pre-empts serious calamities and occurrences such as drought, floods and global warming that would otherwise take up a lot of resources to deal with their eventualities. Countering the root cause of climate change will help rehabilitate degraded areas and conserve ecosystems that are under threat. In particular, keeping the beneficial relationship between the environment and economy forefront in national development planning and policy formulation is key to ensuring that all development intervention remains within the carrying capacities of the natural resource base (ROK, 2009).

In the Kenya National Environment Action Plan of 2009 - 2013, it is held that mitigation of climate change should involve undertaking research on its impact on the environmental, social and economic sectors; enhancing analysis and exchange of relevant information, experiences and adaptation among the stakeholders and policy makers as well as improving inter-sectoral coordination (ROK, 2009). And this is where the media are pivotal in gathering and disseminating information regarding the environment, including climate change.

In a bid to provide its citizens with a clean, secure and sustainable environment by 2030, Kenya has set such goals as increasing forest cover from less than three percent of its land 
base at present to four percent and to lessen by half all environment related diseases by 2012 (Environment and Vision 2030, 2012). In particular, the government endeavours to promote environmental conservation to achieve the MDGs, improving pollution and water management through the design and application of economic incentives and commissioning public-private partnerships for improved efficiency in both water and sanitation delivery.

Further, the country aspires to enhance its disaster preparedness capacity in all disaster prone areas and improve the capacity for adaptation to the impacts of global climate change. Similarly, harmonising environment related laws for better planning and governance remains a top priority.

As stipulated in the Kenya Vision 2030's First Medium Term Plan (2008 - 2012), the government is to strengthen linkages with institutions of higher learning, including universities and other research institutions through joint capacity building in environment related disciplines. This will be done through short term training, establishment of university based science parks as centres of technological innovation, development of environmental and hydrological monitoring of programmes in major water catchments as well as effective and environmentally friendly solid waste recycling technology usable at the community level in major urban areas (ROK, 2008).

In collaboration with the universities, the government further endeavours to develop priorities concerning the environment, water and sanitation to guide both the public and private sector research and management interventions. These pieces of work greatly informed this paper.

\section{ROLE OF MEDIA IN CLIMATE CHANGE COVERAGE}

The role of the media in raising public awareness as well as mobilizing global citizens to act to avert impeding disasters due to climate change is extremely important. This is so, especially in the continent of Africa which is considered to be least responsible for and least informed about climate change, yet the most affected by the disastrous phenomenon (ENAJS, 2012).

According to ROK (2009), information is a fundamental resource upon which organizations, countries and individuals depend on managing their affairs. These pieces of information include those involving climate changes. For example, in the decision making process, information is required to formulate objectives, set targets as well as guides in the implementation of the relevant programmes. It is worth noting that in order to make an informed decision about policies and priorities, there is need to establish a strong, authoritative data gathering mechanism. Additionally, reliable and comparable information will allow the organization to develop indicators and link them to other critical issues like agriculture, health and poverty (ROK, 2009).

The implementation and dissemination of environmental information is fundamental to enhancing public involvement and participation in environmental management that leads to change in behaviour resulting to responsible living and interaction with the environment. Unfortunately, environmental information dissemination and networking technology have not received high attention and priority for quite long compared to other sectors. Accordingly, lack of capacity, poor coordination and linkages, documentation, utilization and preservation of indigenous knowledge are some of the key issues affecting environmental information and networking at the community, civil society, private sector, learning and government institutions and international levels (ROK, 2009). Thus there is need to develop a framework to support country- level integrated environmental assessments and reporting at all levels. 
Among others, the civil societies including the media need to strengthen links between researchers, communities and policy makers for the smooth flow of information and advocacy. Essentially, the communities need to be empowered and encouraged to actively participate in environmental issues including those to do with climate change. As stipulated in ROK (2009), Kenya considers climate change as a priority issue under the environmental disasters and hazards implementation strategy. In particular, the objectives, output and the anticipated activities to have been undertaken by 2013 are all clearly outlined (ROK, 2009).

Kiai and Karembu (1999) assert that environmental concerns have not been given the critical attention they deserve in many developing countries. Accordingly, environmental issues remain more visible in policy documents but wanting in implementation. Such lack of concern is evident in both the media as well as general public. A study carried out by Gichana and Owaka (2002) on environmental articles published in specialized columns found that the print media in Kenya had only a few articles which did not give sufficient information on environmental issues.

Further, Kiai and Karembu (1999) argue that journalists regard environmental stories as 'dry' and less lively compared to political, business and entertainment ones. In addition, they argue that many journalists feel that environmental issues are too technical thereby leaving them to such international players as UNEP, environmental experts, professionals, academics and lobbyists. They conclude that both the media and the public have failed to set the environmental agenda consistently, despite its contribution to sustainability of the future of the earth as well as humanity. However, these studies do not address the challenges faced by journalists while covering climate change, a gap that this paper makes an effort to fill.

\section{CRITICAL CHALLENGES IN CLIMATE CHANGE REPORTING}

According to the Kenya Vision 2030 (ROK, 2007), the government aspires to upgrade the capacity of the relevant institutions for enhanced environmental data and information coverage as well as application. In the vision's implementation matrix, the government commits itself to promoting and safeguarding the state of environment for economic growth. It particularly singles out raising environmental education and awareness among citizens as a top priority (ROK, 2009).

From the foregoing literature, the role of the media in contributing to the public understanding of climate change becomes crucial. Clearly, the media have a key role to play in putting and keeping sustainable development and climate change on the news agenda. However, research shows that the media do not pay sufficient attention to climate change thereby failing to keep climate change on the news agenda long enough to inform opinion. Issues of sustainability and environmental justice are often marginalized in reporting compared to, say, coverage of such events as the Commonwealth Games held in New Delhi, India and Soccer World Cup in South Africa in 2010 (ENAJS,2012). This is reinforced in the Science Daily (February 25, 2009), where it is documented that the media continues to focus its attention on health, the economy or crime thereby drawing public attention away from the issue of climate change. This scenario is not likely to stimulate the sort of public attention that prompts concerted political action.

Further, journalists do not fully understand the science behind climate change. They are therefore, unable to communicate issues on climate change effectively (ENAJS, 2012). But journalists can succeed in the difficult task of presenting a complicated story yet make it both comprehensible and appealing to a lay audience (Edwards, n.d). Accordingly, one of the key 
ways to do this is to have a strong storyline as the art of story telling applies to science as well as any other field.

Similarly, the gathering of information alone by journalists is threatening for many companies, organized crime groups, governments and the various kinds of intermediaries that profit from misuse of the environment (World Federation of Science Journalists - WFSJ, 2009). For example, in Cambodia, the Philippines and Indonesia, where logging companies often have close ties to government officials, reports on deforestation have led to deaths as well as arrest of journalists. Since the Rio Summit in 1992, there has been an increase in violent attacks against journalists covering environmental issues (Pallab, 2009).

In addition, journalists face problems, especially if criticizing government decisions. They risk such penalties as imprisonment or worse for publishing their stories. Such cases have been reported in China amongst other countries (WFSJ, 2009). \#\#\#\#

Indeed, journalists in Kenya have had their share of the wrath in matters involving reporting destruction of the environment, particularly where influential individuals within government ranks are concerned. There is also the critical question that stares in the face of journalists all over the world. This is to do with whether to always pursue the sensations even when risking conveying an unbalanced picture. Indeed, a number of reports on climate change are slightly lumpy and not balanced. Thus, they face the challenge on how to ensure accuracy, fairly represent climate change issues and at the same time communicate a story that grips and motivates the audience (Edwards, n.d).

At times, coverage on climate change is overly alarmist. Among others, this kind of reporting makes people feel hopeless about the issue and so feel that there is no point in trying to tackle it (Pallab, 2009). Journalists also encounter challenges while reporting on environmental issues, including climate change, to a reader suffering from poverty, hunger, disease, drought or even a decision maker who is acting to solve actual urge problems (Dalia, 2010). Evidently, with such actual challenges in Africa, including Kenya, environmental journalists are working in bad conditions.

In a nutshell, journalists are facing a long list of other challenges when reporting climate change in the developing world including shortage of accurate national or even regional information, inadequate scientific research, low level of cooperation and coordination among the different stakeholders and lack of interest among editors in chief as well as readers (Dalia, 2010).The following are considered to be crucial prospects that journalists as well as the relevant policymakers could explore further in an effort to help address these pertinent challenges.

\section{PROSPECTS OF CLIMATE CHANGE REPORTING IN KENYA}

According to Nisbet (2009), time has finally arrived in the developing countries for major policy action on climate change to be taken. Given the numerous challenges facing journalists in covering climate change, it is imperative that sustainable intervention measures be formulated and implemented accordingly. This is particularly important if Kenya is to achieve the goals stipulated in the Vision 2030 development plan, especially those meant to enhance food security, health and environmental sustainability. Indeed, the media should be encouraged to be as free as possible and widely report on climate change and related issues so as to raise public awareness and to even put pressure on the government, where necessary, to keep its promises including reducing carbon dioxide gas emissions. The Rio Declaration clearly 
states the need to engage and involve the general public. This role is best played by the media (WFSJ, 2009). In addition, the Rio Summit emphasizes on the need to protect environment journalists.

Additionally, there is need to create a panel of top climate change reporters, specialists and scientists who are equipped with the knowledge, skills and attitudes so as to improve reporting as well as analyzing relevant issues on the environment, agriculture, science, economy and politics. In particular, reframing the relevance of climate change in ways that connect to a broader coalition of people as well as repeatedly communicating these new meanings through a variety of trusted media sources and opinion leaders is paramount (Nisbet, 2009). Among others, successfully reframing climate change means remaining true to the underlying science of the issue.

Commendably, to support environmental as well as science journalists in Kenya, the Kenya Environment and Science Journalists Association was founded in 2007 (www.kensja.org). It is worth noting that this body is admitted to the World Federation of Science Journalists. Among others, the association assists journalists to link up with news sources as well as secure relevant scholarships and fellowships. In addition, some collaborators do sponsor journalists to go out in the field and cover and report matters involving climate change.

On its part, the government should consider launching a mentoring scheme to produce journalists for better grassroot coverage of climate change in the local newspapers, radio and $\mathrm{TV}$, especially at this juncture when Kenya is hard hit by consequences of climate change. It is important that such journalists, specialists and scientists with diverse skills in communicating science, economic, agricultural and environmental matters, including climate change, meet to explore related issues, provide training, solve problems, network and discuss effective ways to engage people. In particular, there is need for such journalists, specialists and scientists to take turns in sharing experiences of how to tackle the various challenges involving investigative reporting in the field of climate change and other environmental issues.

Similarly, it is paramount that journalists accurately, impartially and critically report on climate change issues so as to ensure that the viewers, listeners and readers trust what they say (Pallab, 2009). Journalists should also be keen on formulating strong storylines. The art of story telling, it has been postulated, is relevant to science just like it does in other fields.

And, apart from having a panel of climate change journalists, all other journalists, whether reporting on business, politics or entertainment should be climate change correspondents in order to make coverage on climate change as wide as possible. In addition, arrangements should be made for journalists to go to particular places to see for themselves the impact of climate change. Upon acquiring such first hand information on climate change issues, journalists could then report accurately, fairly and reach the widest and relevant audience possible.

\section{CONCLUSION}

Climate change is a new environmental challenge to be added to those of poverty, hunger, disease and conflicts in the developing world which are major stumbling blocks to social, economic and political development. As per the report compiled by the Center for Climate Change Communication (2012), limiting climate change and protecting people and ecosystems from the unavoidable changes in the climate will require smart, and in some cases hard decisions from members of the public and policy makers. Going by scientific research, climate 
change will have a significant impact on such sectors as agriculture and tourism which are some of the major sources of livelihood in Africa, a situation that will in turn exacerbate the already fragile situation. It is vital therefore, that the public is made aware of the impacts of climate change and the need to play an active part in attempting to surmount them.

Among the strategies for delivering flagship programmes and projects outlined in the Kenya Vision 2030 is that of promoting the free flow of information so as to strengthen engagement between the government, civil society and private sector. It is imperative therefore, that climate change coverage remains at the top of the media hit parade in the 21st Century since it is an up to date issue. The media should take responsibility and create awareness among both the public and decision makers in order to take the required action early enough to avoid worst situations.

But more importantly, journalists in Kenya and Africa in general should cover climate change in both a professional and comprehensive manner. In order to effectively play this crucial role, they should have sound knowledge on matters involving climate change, related fields as well as pertinent economic and political issues. On their part, governments and environmental scientists should provide accurate data while the journalists should simplify and link it to the reader's daily life taking into account its social, economic and political implications. This is important, especially if Kenya is to achieve the goals outlined in Vision 2030 and convince the decision makers that serious action should be taken immediately.

\section{References}

BBC World Service Trust (2009). Research to Gauge Public Understanding of Climate Change. London: BBC Trust.

Center for Climate Change Communication (2012). Fairfax: George Mason University. Available at: http://www.climatechangecommunication.org/. Accessed on September 10, 2014.

Dainton, M. and Zelley, D.E (2005). Applying Communication Theory for Professional Life: A Practical Introduction. London: Sage.

Dalia, A.S (2010). Challenges Facing African and Middle Eastern Journalists in Reporting Climate Change. Paper Presented During the2010 Annual Meeting held at San Diego.

Edwards, R. (n.d). Media Coverage of Climate Change -Effective or Beneficial? Available at: http://www.britishcouncil.org/india-projects-lcf-communicating-climate-change-htm. Accessed on February 27, 2014.

\section{ENAJS (2012). Ecquid Novi: African Journalist Studies, 33(1). http://www.tandfonline.com/dvi/abs/}

Environment and Vision 2030. Available at: http://na.unep.net/atlas/kenya/downloads/chapters//kenya. Accessed on October 21, 2014.

Eskjaer, F. M (2009). Communicating Climate Change in Regional News Media. International Journal of Climate Change Strategies and Management, 1 (4):356-367.

Gichana, M and Owaka, P.S (2002). A Comparative Content Analysis of Specialized Reports in Science and Technology in the Daily Nation and Kenya Times Newspapers. Nairobi: University of Nairobi.

Itai, M (2005). Community Radio: A Voice for the Poor. Better Local Communications can Boast Development, Democracy. African Renewal, 19(2), 4-5.

Kiai, W and Karembu, M (1999). Understanding Environmental Communication in Kenya. Nairobi: African Council for Communication Education.

McCombs, M and Shaw, D (1972). The Agenda Setting Function of Mass Media. Public Opinion Quarterly, 36, 176187.

McQuail, D (2005). McQuail's Mass Communication Theory (5th Ed). London: Sage.

Nisbet, M.C (2009). Communicating Climate Change: Why Frames Matter for Public Engagement. Available at: htt://www.environmentmagazine.org/Archives. Accessed on March 2, 2014. 
Momanyi, E., \& Nyatuka, B. O. (2015). Communicating Climate Change in Kenya: Status, challenges and Prospects. Advances in Social Sciences Research Journal, 2(8) 75-84.

Pallab, G (2009). Media Coverage of Climate Change: Impacts, Policies and Politics. WFSJ.

ROK (2007). Kenya Vision 2030. Nairobi: Ministry of Planning, National Development and Vision 2030

ROK (2008). Kenya Vision 2030: First Medium Term Plan (2008-2012). Nairobi: Ministry of Planning, National Development and Vision 2030.

ROK (2009). Kenya National Environment Action Plan 2009 - 2013. Nairobi: Ministry of Environment and Mineral Resources/NEMA

ROK (2010). National Climate Change Response Strategy. Nairobi: Ministry of Environment and Natural Resources.

Science Daily (February 25, 2009).Climate Change is not taken Seriously because Media is not Highlighting its Significance; Experts Say. Available at: http://www.sciencedaily.com/releases/2009/02/090225073213.htm. Accessed on July 10, 2013.

UNEP (2009). Climate Change Science Compendium. Nairobi: EarthPrint.

WFSJ (2009).Climate Change Reporting: Science Journalists More Important than Ever. World Federation of Science Journalists 